\title{
Eportfolio Implementation in a Multiple Campus University Environment 6 -Academic Teacher Continuous Improvement
}

\author{
Marie B. Fisher, Andrew J. Hill \\ Australian Catholic University, Australia
}

\begin{abstract}
At the Australian Catholic University (ACU) an ePortfolio may be used as a product, to display parts of one's Personal Learning Environment (PLE), or as a process, referred to as a Personal Learning Network (PLN). This is challenging to institutions and their Executive, as academics can use it both as an assessment 'of' learning and as a vehicle 'for' learning. It promotes metacognitive awareness of learning (awareness of one's own thinking and problem solving) providing opportunities for selfdirected learning by exploiting its digital affordances, enabling users (teachers or students) to reflect upon, profile, and transform learning, teaching, and engagement with peers in one's profession using a Scholarship of Learning and Teaching (SoLT) approach [1]. Reflection is an essential part of academic learning and continuous improvement. In Teacher Education courses, community reflective practice [2] helps profile evidence used to show continuing achievement against professional teaching standards in an evolving life-long learning journey.
\end{abstract}

\section{Introduction}

The aim of this paper is to outline the challenges that continue to hinder ePortfolio implementation with an integrated technology and evidence based pedagogy, and to share the strategies we used to overcome these obstacles (based on our own observations and reflection). Secondly, as one recognises the benefits of the transformative learning affordances of a PLE and PLN, it is hoped that there is scope to improve the implementation, promotion and adoption of ePortfolios across the Higher Education sector by sharing our journey and seeking feedback on our experiences from the global community.

The Executive at our University are faced with a significant set of challenges when encouraging adoption and integration of the ePortfolio tool, Mahara. An institutional approach to administering e-learning tools like ePortfolio is preferable to allay suspicion about their value. Another benefit of an institutional approach would be to increase uptake of the tool for PLE/PLN purposes.

\section{Literature Review}

Time poor academics, varying degrees of digital literacy [3], [4] resistance amongst influential members of the academic community and provision of a skills deficit based 'training' model [5] for professional development are hurdles that the academic community need to overcome. In a multiple campus environment, showing how a PLE and PLN helps students demonstrate the connection and nexus between university teaching, pedagogy and teacher competency, in professional experience components of their units of study, would be a way forward to increase adoption and implementation [5].

To encourage academic staff in different faculties, in a multiple campus university environment to collaborate as well as integrate technology tools with learning and teaching pursuits it is important to:

a) Scaffold instructions;

b) Encourage modelling by homophilous 'opinion leaders', as identified by diffusion research, to provide exemplars that build confidence and capability;

c) Determine strategic approaches and activities to encourage uptake and engage not only in their own personal learning environment but in their personal and extended learning networks so they realise 'what's in it for me?'

d) Trial different approaches (template designs, group submissions) to learn how they interact as well as meet, or do not meet intended learning outcomes.

There is still a lack of understanding amongst academics about how engagement in Scholarship of Learning and Teaching (SoLT) is used and understood in universities. Engaging in SoLT practice needs to be clearly defined in the sector so that academics are confident they understand the definition, value of engaging with colleagues in this way and how to conduct SoLT research [20].

Engagement in Scholarship of Learning and Teaching practices (SoLT), such as reflecting on learning activities, teaching, dissemination of 
information about approaches and sharing with colleagues, has important implications for academic development. The uptake of ePortfolios by academics for professional development purposes would increase if there were more opportunities to share practice with colleagues with a view to capacity building across schools, faculties and multiple campuses [4], [20].

By informing others and building communities of practice, supplemented with common 'shared' resources, academics would be more likely to become involved if they feel they have ownership of their personal learning when it is integrated in academic work much like the 'simulated nurses station' discussed by Karsten and others in 2015, where students had a common place (in an ePortfolio computer lab) to chart activities and discuss their work [6].

Academics are less likely to express concern about not having enough time for engagement in academic and professional development if it is perceived as collegial and necessary rather than a criticism and a remedy for poor practice. [4], [18].

Further benefits of engaging regularly in SoLT is that it can be used as a means of demonstrating excellence while at the same time raising the profile of high quality teaching; a means of showing 'operational' frameworks, assess teaching quality and as a tool for developing academics.

Our academics already have a Teaching Criteria and Framework to use for a guide on what constitutes high quality transferable evidence of excellent teaching aligned to academic standards [12].

At the time of writing the Teaching Criteria and Standards Framework is expected to be reviewed in 2018 and improved in response to feedback from colleagues across our University. An important point to note is that 'excellence in teaching teams' is perhaps a more positive method of promoting excellence and collaboration with colleagues than focusing on the individual.

Academics are more likely to persevere with integrating ePortfolios to help them provide excellent learning and teaching experiences for their students, by involving them in their learning designs [6] as well as their colleagues, to accommodate collecting, profiling and sharing evidence of professional practice which will also help to improve their personal learning [7].

\section{ACU Structure}

The Australian Catholic University was established in 1991 following the consolidation of four tertiary institutions in Eastern Australia. There are 7 domestic campuses in 4 states, New South Wales (NSW), Queensland (QLD), Victoria (VIC), South Australia (SA), and 1 territory, Australian
Capital Territory (ACT). [4] An additional international campus, a joint venture with the Catholic University of America, was opened in Rome in September 2015. The University emerged from vocationally oriented colleges established by clergy from a number of Catholic religious orders eg teachers and nurses.

The larger campuses situated in major cities in Sydney, Melbourne and Brisbane, are managed by 3 Associate Vice Chancellors. Ballarat and Canberra campuses are led by a Campus Dean. Most campuses teach undergraduate and postgraduate courses in the 4 faculties: Education \& Arts, Health Sciences, Law \& Business, and Theology \& Philosophy. Each state or territory has their own legislation and requirements for professions in Law \& Business, Education, Nursing, Paramedicine, Psychology, Physiotherapy and Social Work making the issue of uniformity with learning tools like ePortfolios problematic [4].

In addition, people located in various jurisdictions in Australia such as New South Wales (NSW) have a different culture or approach to accreditation to say Queensland (QLD). This is due to different structures and priorities in the formation of regulatory or professional accreditation boards. Therefore, state based differences considered as dominated by larger city 'cliques' can become a barrier to sharing, collaboration or developing a more streamlined approach to accreditation in Teacher Education as well as Nursing, Law and similar professions [4].

Based upon the authors' own experience and observations, a 'centralised' approach to change the design, development and implementation of national templates from the Learning Management System [LMS]) has failed because it does not address the different contexts upon which they are imposed, and include a variety of assessment instruments and accommodate student learning styles [7].

\section{Curriculum Changes for Teacher Education}

Teacher training, quality teaching and professional teaching standards in Australia came under the spotlight again in recent years due in part to rapidly changing technology that needs to be integrated into learning and teaching as well as a robust response to political pressure [8]. As a result of these required changes most units of study in the undergraduate teaching degrees had to be rewritten to integrate a professional experience component requiring students to build an ePortfolio.

In this space they could not only store evidence of professional practice against the Professional Teacher Standards, but profile and build upon what they had learned through reflective experience in achieving teacher competence. Emerging changes in 
professional experience aspects of the teacher education curriculum aligned closely with standards for teachers are not unique to Australia.

A recent study of reflective practice journaling outlined four concepts regarding preparation of teachers for the profession namely: dispositions (character, intellect, care) identified and aligned to professional US standards for teachers; reflection on one's practice with a view to continuous improvement reflective thinking ; and reflective journaling [9].

These four concepts have been accommodated in the changes occurring since 2014 to the present in Australian Teacher Education accreditation requirements [8].

\section{Impact of EPortfolios for Achieving Professional Teaching Standards}

Based on the authors' teaching experience and observations, integration of professional experience into units of study across a number of undergraduate and postgraduate degrees is not an easy task for various reasons. Experience shared by the primary author in her previous role as a degree co-ordinator and as a teacher education lecturer, indicates that this task involves considerable consultation with fellow teachers, preferably involving students, Executive of the respective faculty and our University as well as critical self-reflection upon one's own approaches to learning and teaching [8], [9].

Academic staff may consider that they have had extra work imposed upon them or lack the necessary digital literacy. This may result in some staff being reticent to engage pedagogy with technology in new ways to achieve learning outcomes [3].

In addition, in a multiple campus environment with diverse cultural differences across the campuses there may be a perception that only one or two campuses have 'any say' in how these changes are marketed to staff and implemented consistently utilising technology [4].

As a result, the senior academic staff, faculty and University administration become frustrated with the perceived lack enthusiasm or in some cases resistance to adoption and integration of University supported technologies. The observation that academic teachers find the design of ePortfolios problematic has been supported by recent research conducted by Silva et al, 2015, who raise the significant issue that it is time to involve students who are also stakeholders in ePortfolios including their Personal Learning Environment (PLE) [7].

So the question remains - how should our University assist academic teachers transform their learning, teaching and adoption or integration of this technology and at the same time involve key stakeholders, their students?

\section{Faculty of Education and Arts, (SoLT Practice)}

The example of professional practice that will be presented is included to show the considerable benefits of ePortfolios for profiling professional experience (developing PLEs and professional networks) acquired during practicum in schools, community engagement and through university study. Using ePortfolios in this way may seem simple enough for university students provided that they are involved in the development and are able to demonstrate through reflection and acquiring evidence of professional practice, how their experiences transformed knowledge, skills, attributes.

This scholarly practice should support their learning with relevant literature and where possible use real life examples. However, care must be taken when showing images (as evidence) as parents for children under 18 years of age and others must give written permission to use or display images or video material.

It is important to adopt strategies to profile this evidence (integrating pedagogy with technology) into Mahara. Mahara is the ePortfolio hosting tool supported by ACU and, at the time of writing, by most teaching professional standards accrediting bodies.

To accommodate the changes to requirements for professional standards for teachers the authors were approached by the National School of Education in the Faculty of Education and Arts (FEA) for assistance in developing an ePortfolio workshop in collaboration with the faculty executive that would begin the journey of developing a (PLE/N) by creating opportunities or affordances to:

a) Explore with participants how a reflective process could be scaffolded with students;

b) Develop an assessment rubric in consultation with participants;

c) Investigate ePortfolio template(s);

d) Explore peer learning in self-managed groups;

e) Design a Community of Practice model for diffusion of ideas, experience and collaboration when implementing ePortfolio across the Education curriculum [10].

Design and development of this workshop took more time than anticipated as it had to be negotiated between at least two senior executives as well as incorporating input from academic teachers who communicated mixed feelings about the changes to their units.

The authors observed that some people were enthusiastic about integrating the same University supported ePortfolio hosting system for all units required to have a professional experience component encouraging PLE [5]. Other academic teachers, with considerable influence on their peers, 
for historical reasons, were not keen to change their practice [10]. It was evident to the authors that to change behaviour, motivation, increase adoption and improve practice, an enthusiastic academic who had learned how to use the hosting system effectively and modelled this with his students would have more chance of positively influencing those resistant to change to become adopters [10].

The workshop commenced with an address from the Executive Dean explaining that support and assistance would be available to this group to enable them to help their peers. She further explained why these 'experts' had been gathered together to develop a unified approach to integrating professional experience into three Education units initially. The perception of the authors was that her approach was aimed at:

a) a means to achieving institutional change and

b) streamlining 'individual' academic work [7].

A generic approach to developing rubrics for marking or accrediting was necessary to reduce duplication of rubrics, assessment instruments and dispense with unnecessary administration and provide a benchmark for new academic staff who may be less experienced than this group. [11]. A common template, with minor alterations, can only be supported by the National (centrally located) Learning and Teaching Centre at ACU.

At the time of writing there have been no updates to report from the faculty on how successful the integration of ePortfolio reflective practice assessment has been in those core units of study. This may be due to significant structural changes to degree programs that are not yet complete.

\section{Transforming Learning and Teaching Approaches: Explored}

The main transformative learning approach used in developing student ePortfolios at ACU in the Education and Health Sciences faculties is reflective practice [4].

At ACU Education and Health Sciences academics and students continue to be active users for accreditation of teachers, nurses and paramedics [2], [3].

A simple reflective practice can be used to encourage metacognitive awareness by:

a) Identifying what is working well? What learning strategies employed produced good results?

b) What needs changing? If my learning outcomes were poor, what other strategies could I use to improve my practice?

c) What are we learning? How can I 'transfer' my prior learning into this context?

d) Where do we go from here? How do I reassess and adjust my goals [2]? This approach could help reluctant staff take the first steps to profile their own experience for a particular purpose such as promotion or fulfilling probation requirements.

Although academic staff reported informally that they are committed to their own learning through self-reflection there are still hurdles they need to overcome. The authors have observed through facilitation of workshops and other project work that the reality is that many academics are or perceive they are 'bogged down' with being time poor, concerned about lack of recognition and, despite their keenness to improve and contribute to excellence in teaching, want to know: What is in it for me [10]?

Boud and Brew suggest that academics need to develop across a range of areas so that they can cope with the changes in their discipline as well as the nature of their role or roles [18]. So influencing a change in behaviour or management of resistance to participation in collaborative ventures will only occur when there are 'opinion leaders', given real incentives, which are able to diffuse ideas, and gather feedback from schools located in faculties.

The authors of this paper observed that the 'Opinion leaders' who were good communicators, engaged well with colleagues and practice scholarship of teaching (by sharing their experience which included integration of technology, to help others) are a powerful, yet positive, force for change. A recent article by Thomson and Trigwell have suggested that not all colleagues transform and improve their own professional learning from reading and writing about their practice [19].

Some academics may improve their practice and understanding by engaging in informal professional conversations with more experienced colleagues, collaboration to streamline processes or if we consider how the authors were supporting these staff in the National School of Education, to facilitate professional conversations. These conversations had to take place to build rapport, trust and confidence to help academic teachers engage with the set up and establishment of standard templates for teacher education practicum for units of study in degree Bachelor or Education degree program in the ePortfolio hosting system, called Mahara [19].

\subsection{Scaffolding Critical Reflection}

The ACU executive had introduced some new frameworks for teaching and capacity building to help staff and supervisors effect cultural change through reflection and help academics with their career progression. Part of this process is to improve digital literacy and capacity building across our university and with external organisations.

In 2016 the Teaching criteria and standards frameworks were introduced to provide academic teachers and their supervisors with 'clear, objective and consistent criteria that will enable excellence in 
teaching and engagement in their own professional development.' [12].

The development and introduction of this Teaching framework has been a positive step towards valuing teaching and providing pathways for career advancement and highlight the benefits of keeping a teaching portfolio while at the same time encouraging adoption of critical reflection as a strategy to achieve continuous improvement.

The seven teaching criteria include:

1. Design and planning of learning activities

2. Teaching and supporting student learning

3. Assessment and giving feedback to students on their own learning

4. Developing effective learning environments, student support and guidance

5. Integration of scholarship, research and professional activities with teaching and in support of student learning

6. Evaluation of practice and continuing professional development

7. Professional and personal effectiveness [12].

Integration of scholarship and professional activities with students and colleagues is an important aspect of academic teaching. The authors have observed over the last 5 years that many teachers are successful when improving their teaching and learning opportunities for students but lacking the time or commitment to customise their body of evidence of their own practice for a particular purpose such as academic promotion effectively [14].

At ACU the Graduate Certificate in Higher Education (GCHE) has recently been reviewed in the last eighteen months, revised and aligned with the new ACU Teaching Criteria and Standards Framework implemented in 2016 [12]. Teaching staff who enrol in this program typically study one unit per semester over two years and are encouraged to not only collect evidence of academic teaching and scholarly work in a teaching portfolio but critically reflect upon theoretical and practical interpretations on higher education teaching [13].

It is expected that academics studying for this award will develop the ability to focus inwardly on their own practice as well as outwardly gauge the impact of changes they make to learning and teaching in their subject discipline [14].

The four units in the GCHE focus on Learning and Teaching Theories in Higher Education; Curriculum Design and Development, Technology Enhanced Learning (including use of ePortfolios) and the capstone unit Scholarship in Higher Education [13]. It is a fully online course that encourages use of technology to facilitate discussions, activities and collaborations on real life projects and learning activities.

EPortfolios could be used as a more convenient tool or vehicle for learning. It has the potential to help staff manage collaborative relationships through group activities and reflect on the nexus between scholarship, research, teaching and personal learning (PLN) [1], [2]. Staff would be able to document their personal learning journey as well as adopt alternative strategies for career development aligned to the seven ACU Teaching criteria.

In recent research on Higher education development, Leigh suggests that critical reflection needs to be substantiated by theoretical and practical interpretations of what it means to reflect [14]. She acknowledged the benefits and importance of critical reflection as a means of judging improvement in one's practice against learning outcomes or achievement of certification in teaching. However, self-awareness and the ability to process events that arise in the environment in which you work such as dynamics in a classroom, lecture space or meetings with colleagues are another important aspect of one's professional development [14].

Academics in all disciplines need to be taught how to critically reflect on their own learning and teaching activities by using a 'scaffolding' approach to ensure that they understand the relevance to their own scholarly pursuits, have clear guidelines and exemplars relevant to their discipline [15]. If academics know how to approach critical reflection then they will be less inclined to resist or resent using this approach for continuous improvement. Using the ePortfolio tool could be a much easier way of using evidence collected for different reasons eg seeking promotion or working in partnership with another school for multiple purposes

By using Peer Observation and reflection on teaching (PORT), a new initiative at ACU facilitated by the Learning and Teaching Centre in partnership with faculties, was implemented in mid-2016. 'Peer observation of teaching is an established developmental tool in face to face settings' [16]. Academics have been very positive about this program and have been willing to report to peers via video on teaching and, at the same time demonstrated that they are more receptive to feedback on their own practice from peers and colleagues [13]. While peer observation is not new professional development in the sector, it appears that it may encourage academics to feel more confident to uptake the ePortfolio tool, to help them build up a teaching portfolio and better understand the benefits of reviewing their scholarly pursuits and student engagement.

Recent research by Gambino suggests that while the ePortfolio technology is easy to learn the 'integrative pedagogy takes time to master' [17]. The authors have observed that when academics are given the opportunity to work on building up their evidence and integrating experiences to benefit others, such as peer review, barriers tend to disintegrate and give way to powerful, productive 
learning and collaboration. When faculties selfinitiate creation of teaching circles or peer mentor colleagues in a safe environment where they are not judged negatively, trust is built and consolidated over time. Gambino's recent research supports the authors' observations that those staff involved in continuous professional development in interdisciplinary collaborations, which may include peer observation and supporting others, are the ones who will increase uptake of technology tools like ePortfolios. By fostering collaboration, ePortfolios can be used as a tool for learning, profiling one's experience and capacity building across ACU.

\section{2 'The Gap' with Adoption of Eportfolios}

To encourage development of one's eportfolio of evidence, changes need to occur in our institution to enable academics to self-select professional development to learn how to engage with pedagogy of eportfolios before building one using the University hosting system, Mahara. As we have documented in previous articles over the last 4 years there is a tendency for staff to be driven by the available technology and not realise the value of collecting evidence for a purpose eg performance review which they then profile for another motivation such as promotion.

Professional development and resources need to be developed in partnership and co-operation across ACU. The Learning and Teaching Centre could work in partnership with faculties to ensure that the resources developed would be considered useful by academic staff. Workshops focusing on the design develop and plan phase detailing what you need in your Teaching or Eportfolio was conducted in early 2012 at ACU for all campuses in the form of a face to face workshop. It was well attended, feedback was positive and some people used what they had learned to achieve promotion.

For various reasons, some relating to our University priorities and some political, influenced by those resisting the technology side of ePortfolios, the workshops were only offered once. Now ACU has an opportunity to redevelop some form of face to face or 'virtual' workshops (and resources) conducted in an online classroom that could support staff in storing and profiling evidence for meeting academic standards detailed in the Teaching Criteria and Standards Framework [12]. These offerings could also be used by academic teachers who are undertaking the Graduate Certificate in Higher Education Teaching (GCHE) at our institution to collect and show how evidence has improved their knowledge of Education frameworks and curriculum development.

Academics working in Education and Health Sciences are very capable of guiding their students with their ePortfolios but some don't really know how to profile their own evidence to mount a case for promotion and other forms of career development. Some academics have reported informally that they do not understand the best way to use the lengthy guidelines for promotion to mount their case as most of their time is taken up with teaching. While others who do manage to achieve promotion appear, from the exemplars to be able to address criteria for promotion rather than submitting an ePortfolio. At the time of writing using an ePortfolio for achieving promotion was not the preferred way of profiling evidence according to the promotion guidelines.

So the authors note that some systems at our institution need to be more streamlined and, if we are going to use ePortfolios or teaching portfolios a uniform approach needs to be communicated with appropriate support. The benefit to academics would be that they would be able to use this knowledge to improve teaching and pedagogy guidance they offer to students which in the long run will mean improved outcomes for everyone. In addition, building collaborative relationships with colleagues is the key to putting knowledge gained from professional development into practice

\subsection{Building Trust, Rapport and Sharing Practice Ideas}

Frameworks and guidelines to help academics achieve teaching excellence can be most useful to academics if they appreciate that their colleagues may have a different, but valid view about their purpose. These views are often revealed in professional conversations with colleagues [19]. In a multiple campus environment, with many sub cultures on each campus, engagement in different modes of teaching and significant change in the Higher education sector there are bound to be some challenges building effective lines of communication and accommodating diverse approaches to completion of academic work.

Academics have different ways of working and communicating. Many prefer face to face communication but that is not always possible at our University [4]. The authors conduct most of their collaborations either via email or using an Adobe Connect Virtual meeting room. When the authors reflected on their writing collaboration it was clear that trust, respect and equal sharing of ideas and strategies were things that developed over time. The initial part of the process was building a model of communication that focused on clear expectations, outcomes and being willing to engage in 'disruptive' conversations to question issues arising in our academic writing and practice in the spirit of continuous improvement and our own professional development. 
To build a successful online or local campus community of practice it is important achieve the following so that it is possible to overcome any conflicts or imbalance of power that can often result from misunderstandings [10]. It could be achieved over time by:

(a)Building rapport, trust and respect between colleagues by getting to know them informally at social or community engagement events on or between campuses

(b)Be fully aware of organisational priorities including the frameworks and guidelines that integrate with teaching while at the same time appreciate the reasoning behind their implementation;

(c)Learn about the tasks and projects that your colleagues are working on and how it might relate to your work and the organisation;

(d)Be willing to be 'disruptive' eg question things (in a positive way), challenge ideas and engage in academic freedom in the spirit of continuous improvement, preferably without any repercussions or reprimands by others;

(e)Keep communication positive, polite and show respect for other viewpoints.

We have identified some of the things we think are important to achieve but how can one build a community of trust that is hospitable?

Getting to know colleagues can be problematic across multiple campuses but not impossible. Meet with colleagues in a more informal way at functions, morning teas, in a short catch-up meeting for a particular purpose [19]. It may be online or face to face with an emphasis on finalising a mutually beneficial task over a period of time or just to do some team building over shared responsibilities such as working with people undertaking course redevelopment or joining learning and teaching committees [18].

While there are many positive outcomes that can be achieved by communities of practice some researchers indicate that the missing step is building positive relationships first to try to address any imbalance of power and unnecessary conflict [10], [14]. In addition, the people engaging in a community of practice need to appreciate the value rather than complaining it is one more thing they have to do.

\section{Community of Practice - (SoLT approaches)}

The authors seek to ask questions about how faculty academics as well as students learn, note observational evidence showing affordances as well as barriers to new approaches to learning and teaching. It is expected that by sharing this knowledge with our domestic and international colleagues we are able to help others develop new approaches to practices in teaching, learning and curriculum. [12].

The ACU ePortfolio model of Communities of practice (CoPs) will be a challenge for the faculties in a number of ways:

Firstly the schools in the faculties on a particular campus may not be able to identify clearly what they need help with due in part to the rapidly changing university environment. The authors noted that CoPs define and develop themselves [10] but it is not clear how Academic Development units can facilitate external support [11].

Ownership as well as 'what's in it for me?' needs to come from the schools in the faculties. In other words how will this benefit one's practice, encourage collaboration and serve professional development needs? This may initially take the form of face to face meetings every two or three months, progressing to virtual meetings with larger groups and then considering what global self-organising events could be included to participate in wider opportunities for collaboration.

This process over time will help reinforce motivation and continuation to engage in learning, teaching and development when integrating pedagogical approaches with technology tools both individually, institutionally and globally [4], [10].

ACU needs to take a longitudinal approach to bringing academics from legitimate peripheral participants to self-directed communities [10]. It has been proposed to use both an institutional and a collective approach to empower academics, support 'bottom up' innovation and encourages continuous improvement.

\section{Conclusion}

The authors have reflected on their own practice and observed through their teaching, facilitating and personal learning (PLEs and PLNs) that encouraging new ways of integrating pedagogy with technology tools is a journey. It may include collaboration with colleagues within and across faculties can be challenging for a number of reasons. Trust, academic support amongst peers and negotiation about key goals needs to be fostered and integrated into communities of practice to transform learning in stages within schools and faculties.

When experience and confidence has been built academics are more likely to become self-directed and self-managed after initial support to build these networks is established. Establishing collaborative relationships between faculties and across academic disciplines is necessary to enable confidence building and develop critical reflective practice models to help staff appreciate how an ePortfolio can be used to show deeper learning and continuous improvement. 
In addition, it is important that the Executive of our University are fully informed about operational as well as change management issues by faculties so they are able to make strategic decisions that will help academic teachers improve their digital literacy, engage in more collaborative learning and teaching and actively involve students in this journey.

Building trust, respect and dignity in a multiple campus environment is a challenge that can emerge as a hidden opportunity. Engagement in professional conversations is one way that these hurdles can be overcome if people feel it is a safe environment to admit they need support to achieve personal and organisational goals.

At our University we must all be willing to embark on this journey exploring ways we can encourage academic staff to become more selfdirected in their continuous improvement rather than resistant to change if they perceive their future as a teaching focused academic is uncertain. Academic work is changing so quickly that it is difficult for institutions to keep up with the demand for support and offer it in an environment that suits all learning styles. Therefore, capacity building across faculties and multiple campuses is important to encourage and develop [3]. [4].

We acknowledge that it will not happen quickly. Therefore, we seek and would like to accommodate global feedback to improve our practice as well as help other universities across the world by sharing our own journey and encouraging academics to engage in professional development opportunities to improve their career options.

\section{References}

[1] Johnson, Ruth. S, Mims-Cox, J. Sabrina \& DoyleNichols, Developing Portfolios in Education: A Guide to Reflection, Inquiry, and Assessment, Sage Publishing, USA, 2010.

[2] M.Marienau \& Fiddler "Developing Habits of Reflection for Meaningful Learning", New Directions for Adult and Continuing Education, Wiley Inter Science Periodical, Vol.118, , Chicago, USA, 2008, pp.75-85.

[3] Simon McIntyre "Reducing the digital literacy divide through disruptive innovation", HERDSA Review of Higher Education, Vol. 1, The University of New South Wales, Australia, 2014. Located at: www.herdsa.org.au (Access Date: 4 February 2016)

[4] Marie B. Fisher, \& Andrew J Hill "EPortfolio Adoption and Implementation in a Multiple Campus University Environment 4 - Disruptive Change and Innovation", International Journal for Infonomics (IJI), Volume 8, Issue 4, London, UK, December 2015.

[5] Ebrahim Rahimi* Jan van den Berg \& and Wim Veen "A learning model for enhancing the student's control in educational process using Web 2.0 personal learning environments", British Journal of Educational Technology Vol 46 No 42015.

[6] Kathleen Karsten, Deborah McMillan Coddington, Regina M. Lehman, Cynthia Pierce, May Tom, and Les Gallo-Silver "Facilitating Interprofessional Collaboration Through ePortfolio: A Pilot Study", International Journal of ePortfolio, Center for Teaching and Learning in the Office of the Vice President for Instruction, University of Georgia \& the Center for Instructional Development and Educational Research, Virginia Tech, USA, 2015.

[7] Mary Lourdes Silva, Susan Adams Delaney, Jolene Cochran, Ruth Jackson, and Cory Olivares, "Institutional Assessment and the Integrative Core Curriculum: Involving Students in the Development of an ePortfolio System", International Journal of ePortfolio [IJEP], Vol.5, No.2. pp.155-167, 2015.

[8] G.Craven,K.Beswick, J.Fleming,T.Fletcher, M.Green, B.Jensen, E. Leinonen, \& F. Rickards "Action Now, Classroom Ready Teachers Report" Department of Education and Training, Australia, 2014.

https://docs.education.gov.au/documents/action-nowclassroom-ready-teachers-report-0 (Access Date: 4 February 2016)

[9] Jeffrey T. LaBelle \& Gabrielle Belknap, "Reflective Journaling: fostering dispositional development in preservice teachers, Reflective Practice: International and Multidisciplinary Perspectives, Routledge Taylor \& Francis Group, USA, 2016.

[10] Linet Arthur, "Communities of practice in higher education: professional learning in an academic career", International Journal for Academic Development, Oxford, UK, 2016.

[11] Terrel L. Rhodes, "Assessment: Growing Up is a Many-Splendored Thing”, Journal of Assessment and Institutional Effectiveness, 5(2), 2015, pp.101-116

[12] Learning and Teaching Centre, "University-wide teaching criteria and standards framework," Australian Catholic University, December 2015.http://www acu.edu. au/policies/807558 (Access Date: 4 February 2016)

[13] Australian Catholic University, "ACU Learning and Teaching Professional Development Website", Australia, 27 February 2017 http://www.acu.edu.au/867844 (Access Date: 4 February 2016)

[14] Jennifer Leigh, "An embodied perspective on judgements of written reflective practice for professional development in Higher Education", Reflective Practice, 17(1), UK, 2016, pp.72-84.

[15] Susan Maree McNaughton, "Critical reflection: scaffolding social responsiveness for first-year students", Reflective Practice, New Zealand, April 2016.

[16 ] Mark H. Jones and Anne-Marie Gallen, "Peer observation, feedback and reflection for development of practice in synchronous online teaching", Innovations in 
Education and Teaching International, 53(6), Open University Repository, UK, 2015, pp. 616-626.

[17] Bret Eynon and Laura M. Gambino, "Professional Development for High-Impact Eportfolio Practice, Peer Review, New York, USA, 2016, pp.4-8.

[18]David Boud \& Angela Brew, "Reconceptualising academic work as professional practice: implications for academic development", International Journal for Academic Development, V. 18, No. 3, Routledge, Taylor and Francis Group online, 2013, pp. 208-221.

http://dx.doi.org/10.1080/1360144X.2012.671771 (Access Date: 4 February 2016)

[19] Kate Eileen Thomson \& Keith Randal Trigwell, "The role of information conversations in developing university teaching?" Studies in Higher Education, Routledge, Taylor and Francis Group online, Australia, 2016.http://dx.doi. org/10.1080/03075079.2016.1265498 (Access Date: 4 February 2016)

[20] Joelle, Fanghanel, Susannah McGowan, Pam Parker, Catherine McConnell, , Jacqueline Potter, William Locke, and Mick Healey, SoTL "Literature Review: Defining and supporting the Scholarship of Teaching and Learning (SoTL): a sector-wide study -", Higher Education Teaching Academy", University of Brighton, UK, 2016. http://178.62.116.57/sotl/documents/literature_review.pdf (Access Date: 4 February 2016) 